\title{
Prediction of biochemical oxygen demand using radial basis function network
}

\author{
Muhammad Noor*1, Joko Lianto Buliali ${ }^{2}$ \\ Informatics Department, Institut Teknologi Sepuluh Nopember, Indonesia ${ }^{1,2}$
}

\begin{abstract}
Article Info
Keywords:

Basis Function Network (RBFN)

Article history:

Received 10 December 2019

Revised 03 January 2020

Accepted 17 January 2020

Published 06 February 2020
\end{abstract}

Water Quality, Biochemical Oxygen Demand (BOD), Prediction, Improvement Relational

Fuzzy c-Means Clustering (iRFCM), Radial

Cite:

Noor, M., \& Buliali, J. (2020). Prediction of Biochemical Oxygen Demand Using Radial Basis Function Network. Kinetik: Game

Technology, Information System, Computer

Network, Computing, Electronics, and Control,

5(1).

doi:https://doi.org/10.22219/kinetik.v5i1.1006

${ }^{*}$ Corresponding author.

Muhammad Noor

E-mail address:

muhammadnoor.18051@mhs.its.ac.id

\begin{abstract}
Biochemical oxygen demand shows the amount of oxygen needed by microorganisms to decompose dissolved organic substances suspended in water. This variable determines water quality. The higher value indicates lower water quality. Obtaining this value requires a lengthy procedure of five days in typical laboratories. This paper proposes to predict biochemical oxygen demand using a radial basis function network with improvement relational fuzzy c-means clustering to set centroid by using 11 parameters that come from water quality records. The dataset used in testing consisting of weekly parameters between 2014-2019. Testing results show performance measurement of mean absolute error, mean square error, root mean square error, mean absolute percentage error, and accuracy using centroid with improvement relational fuzzy c-means $0.15016,0.3677,0.19082,21.64490$ and 78.35510 comparing with centroid from fuzzy c-means $0.16002,0.04021$, $0.19963,22.83184$, and 77.16816.
\end{abstract}

\section{Introduction}

Water is a natural resource required by all living creatures including humans. Good quality water contains high oxygen and low pollution. Water pollution is indicated by a decrease in water quality to a certain level that causes water cannot be used as intended [1]. A reduction in water quality will reduce the usability, productivity, and carrying capacity of water resources. Consuming low-quality water can cause illness and interfere with health.

Biochemical Oxygen Demand (BOD) is usually used to measure the level of water pollution and quality [2][3] because BOD shows the amount of oxygen needed by the organism when breaking up organic matter under aerobic conditions. The breakdown of organic matter means that organisms use this natural material as food and its energy obtained from the oxidation process [4]. Higher BOD values show a reduction in oxygen level in water [5]. Conventional $B O D$ examination in the laboratory requires the temperature to be at a constant $20^{\circ} \mathrm{C} \mathrm{[6].} \mathrm{The} \mathrm{time} \mathrm{needed} \mathrm{for} \mathrm{the}$ oxidation process of organic matter to breaking up organic matter is five days [4]. Therefore, BOD examination of sample water typically needs five days.

In the water treatment industry, conventional BOD measurements are too complicated when used in process control [2][7] whereas the prediction of BOD values needs to obtained directly to know water quality quickly [8][9]. A faster and more accurate approach is required to predict BOD values. The soft computing method was proposed as a useful tool using water quality parameters to predict BOD values. The research on soft computing methods to predict BOD, such as has been conducted by Fanjun et al. using A Fast Growing Cascade Neural Network to predict BOD in the process of wastewater treatment in Beijing [7]. Xiu Li, and Jingdong Song used A New ANN-Markov Chain Methodology to predict BOD values in determining the level of pollution in the port of Tolo, Hongkong [10]. A.A. Masrur Ahmed and Syed Mustakim Ali Shah using an adaptive neuro-fuzzy inference system to predict BOD values in monitoring water quality in Surma River, Bangladesh [3].

This paper proposes a method to predict BOD by using Radial Basis Function Network (RBFN) with Improved Relational Fuzzy c-Means (iRFCM) clustering to set centroids. RBFN has a unique characteristic that the data from input to the hidden layer is processed non-linearly while data from the hidden layer to the output layer are processed linearly. The advantage of RBFN is the fast and efficient computations because the network is feed-forward [11]. The hidden layer uses a radial based activation function. In the activation function, there is a calculation of the distance the training data with the centroid. This distance data is used to calculate the weight of neurons. Therefore, a clustering method is needed to set the best centroid. The weight of neurons in the hidden layer can increase the accuracy of 

predictions. Fuzzy c-Means (FCM) is one of the most popular clustering method however it has several disadvantages, including sensitivity to the initial guesses, unability to handle noisy data and outliers, very large or very small values could skew the mean, and not suitable to discover clusters with non-convex shapes [12]. The problems inherent in FCM can be avoided by using iRFCM because iRFCM used relational data by a matrix that corresponds to measures of pair wise distances (dissimilarity) between objects as data input, and it is not concerned with the relational database [13].

\section{Research Method}

This paper proposes the use of iRFCM to set centroid. The results from iRFCM method are compared with the results from FCM method to find out the performance of each method. The proposed method consists of several stages, starting from data preprocessing to performance measurement as shown in Figure 1.

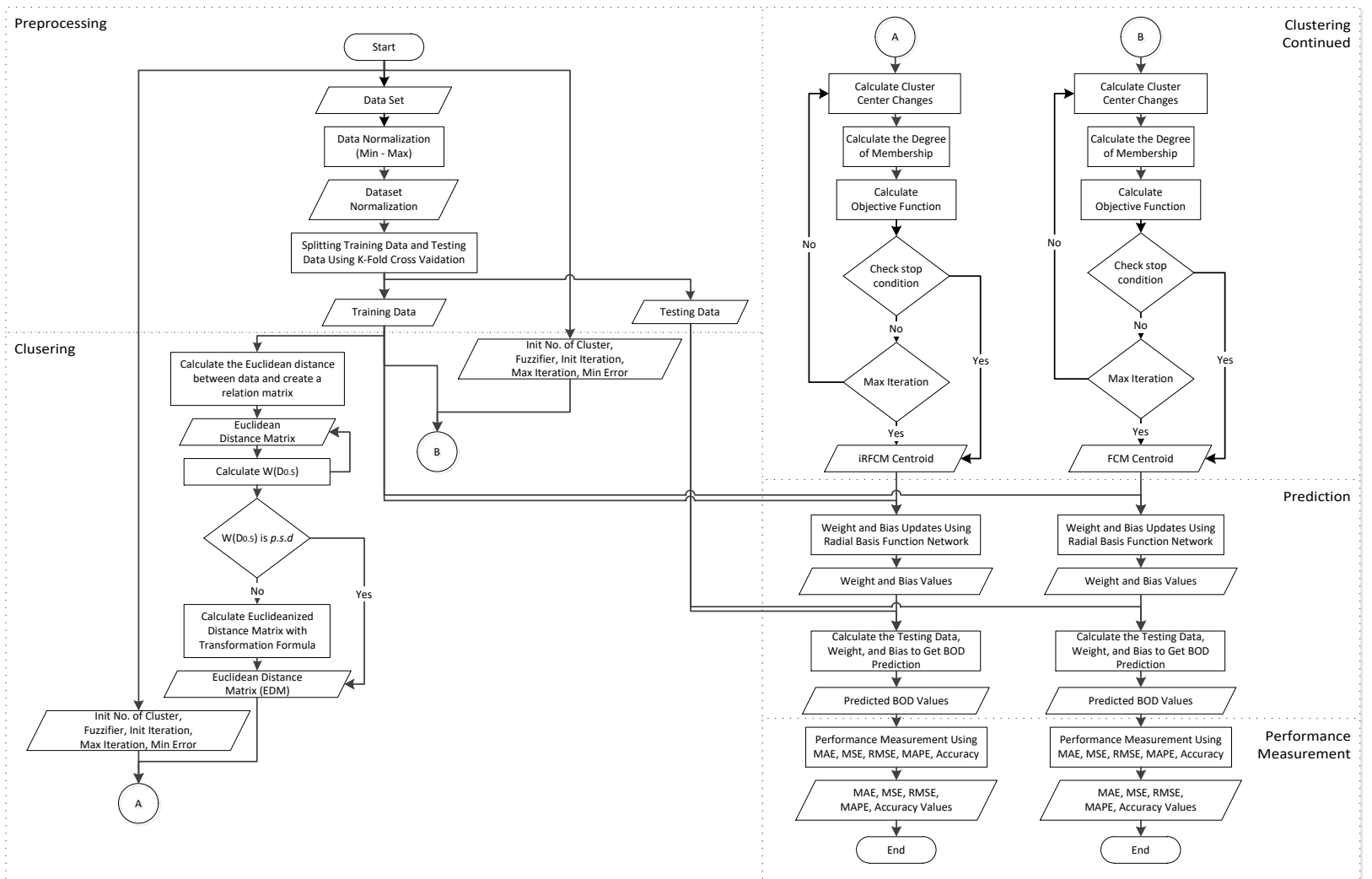

Figure 1. The Proposed Method

The first stage is the preprocessing that consists of the normalization process (by using the min-max normalization method) and splitting data to training data and testing data (by using $\mathrm{k}$-fold cross-validation). The second stage is clustering data to set centroids of training data in both iRFCM and FCM methods. The third stage is predicting stage (by using RBFN method which updates weight and bias). The last step is testing the methods (by measuring the performance of each method). Testing aims to determine which method gives better BOD prediction values.

\subsection{Data Processing}

The data used in this research is a dataset consisting of 256 records of raw water parameters between January 2014 - February 2019 from measurement. Each record consists of 12 parameters including BOD parameter. Table 1 shows 10 sample data from a total of 256 data.

Table 1. Sample Dataset

\begin{tabular}{|c|c|c|c|c|c|c|c|c|c|c|c|}
\hline Temperature & Turbidity & Color & $\mathrm{pH}$ & Alkalinity & $\mathrm{CO} 2$ & $\begin{array}{l}\text { Dissolve } \\
\text { Oxygen }\end{array}$ & Nitrite & Ammonia & Fosfat & Sulfide & BOD \\
\hline 27.10 & 365.00 & 94.34 & 7.65 & 153.11 & 6.86 & 3.10 & 0.01 & 0.90 & 0.47 & 0.62 & 10.00 \\
\hline 27.80 & 121.00 & 61.09 & 7.58 & 167.23 & 8.80 & 4.15 & 0.01 & 0.66 & 0.03 & 0.50 & 13.00 \\
\hline 27.40 & 266.00 & 189.23 & 7.54 & 154.66 & 8.92 & 4.07 & 0.01 & 0.38 & 0.21 & 0.24 & 8.00 \\
\hline 25.00 & 156.00 & 28.65 & 7.67 & 178.21 & 7.62 & 4.79 & 0.01 & 0.06 & 0.21 & 0.26 & 11.00 \\
\hline 25.90 & 223.00 & 100.02 & 7.53 & 138.82 & 8.14 & 4.48 & 0.01 & 0.74 & 0.03 & 0.52 & 13.00 \\
\hline
\end{tabular}

(c) 2020 The Authors. Published by Universitas Muhammadiyah Malang

This is an open access article under the CC BY SA license. (https://creativecommons.org/licenses/by-sa/4.0/) 
Kinetik: Game Technology, Information System, Computer Network, Computing, Electronics, and Control

\begin{tabular}{llllllllllll}
26.20 & 107.00 & 87.04 & 7.43 & 148.83 & 11.06 & 3.98 & 0.02 & 0.67 & 0.11 & 0.31 & 10.00 \\
26.10 & 436.00 & 74.06 & 7.57 & 128.06 & 6.89 & 5.04 & 0.02 & 0.55 & 0.16 & 0.30 & 15.00 \\
26.00 & 78.50 & 14.05 & 7.55 & 155.53 & 8.77 & 4.54 & 0.02 & 0.45 & 0.08 & 0.10 & 11.00 \\
27.40 & 38.60 & 26.21 & 7.71 & 172.54 & 6.73 & 4.19 & 0.01 & 0.24 & 0.19 & 0.13 & 11.00 \\
26.90 & 23.30 & 16.48 & 7.55 & 173.59 & 9.78 & 4.63 & 0.02 & 0.00 & 0.35 & 0.14 & 9.00 \\
\hline
\end{tabular}

In this research, the 11 parameters in Table 1 are used to predict BOD parameter. These 11 parameters can be obtained easily and quickly. The difference ranges of values in each parameter are significant therefore it is necessary to normalize the data with the result that no dominance of each other [14]. The normalization method used is the MinMax normalization method [15] which performs a linear transformation of the input data and produces a balance of comparative values between original data and normalized data. Min-max normalization formula is shown in Equation 1. The range that is often used in this method is $0-1$.

$$
\text { Normalized }[\mathrm{x}]=\frac{\text { minValue }+(\mathrm{x}-\text { minValue })(\text { maxValue }- \text { minValue })}{\text { maxValue }- \text { minValue }}
$$

After normalization, data are split into training data and testing data by using K-fold cross-validation method [16] [17]. The data is converted into a random subset and tested by repeating as many as $k$ values. Each repetition leaves one subset for testing and the other subset for training. Many experimental results show that 10 -fold is the best choice to get accurate prediction [18] therefore in this research 10-fold cross-validation is used as shown in Table 2.

Table 2. 10-Fold Cross-Validation

\begin{tabular}{ccccc}
\hline No. of Folds & Total Data & Data Each Fold & Training Data & Testing Data \\
\hline 10 folds & 256 data & 25 data & 231 data ( 9 folds) & 25 data ( 1 folds) \\
\hline
\end{tabular}

Training data are used to set centroid using the clustering method, weight update and bias values in RBFN. This process is repeated as many as $k$ values (10 times).

\subsection{Centroid Setting}

The clustering process uses training data to set centroid. This centroid is critical in the RBFN prediction method because the centroid is used to calculate the distance between the data and the centroid in the activation function. Also, the number of clusters plays a role in setting the number of hidden layers used. In this research iRFCM clustering introduced by Khalilia [19] is used to set centroids. iRFCM is the development of Relational Fuzzy c-Means Clustering (RFCM) [13] to solve the problems contained in the RFCM method [20]. RFCM cannot perform centroid calculations when the Euclidean distance relationship is negative (non-euclidean) [12][21]. Algorithm 1 shows the steps to set centroid in iRFCM.

Algorithm 1. improvement Relational Fuzzy c-Means (iRFCM).

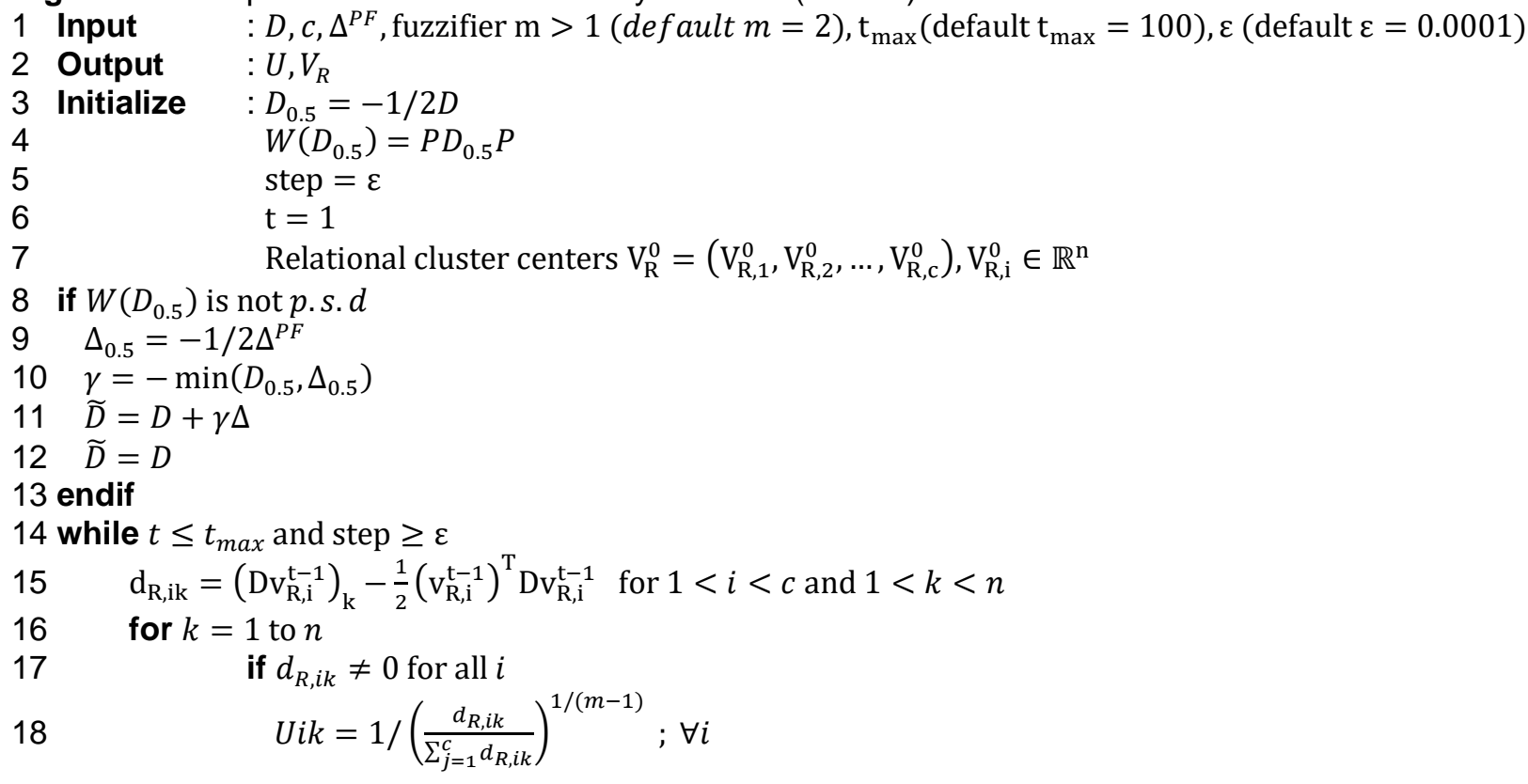

Cite: Noor, M., \& Buliali, J. (2020). Prediction of Biochemical Oxygen Demand Using Radial Basis Function Network. Kinetik: Game Technology, Information System, Computer Network, Computing, Electronics, and Control, 5(1). doi:https://doi.org/10.22219/kinetik.v5i1.1006 


$$
\begin{aligned}
& V_{R, i}^{t}=\left(\mu_{i 1}^{m}, \ldots \ldots, \mu_{i n}^{m}\right) / \sum_{k=1}^{n} \mu_{i k}^{m} \text { for } 1<i<c \\
& \text { step } \leftarrow \max \left\{\left|V_{R}^{(t)}-V_{R}^{(t-1)}\right|\right\}, \max =1<i<c \text { and } 1<j<n \\
& t \leftarrow t+1
\end{aligned}
$$

\section{6 endwhile}

where

$D \quad$ : Euclidean distance matrix, $\left[D_{i j}\right]=\left[\left\|x_{i}-x_{j}\right\|_{2}^{2}\right]$

C : Number of clusters,

$P \quad:$ : Center matrix, $P=I-\frac{1}{n}\left(11^{T}\right)$

I : Identity matrix,

p.s.d : Positive semi definite, where eigenvalues are non negative,

$\gamma \quad$ : Positive constant,

$\Delta^{P F} \quad$ : Power Fit, $D^{\alpha} ; 0<\alpha \leq 1$.

\subsection{BOD Predicting}

The weight of the neurons determines artificial neural network effectiveness. RBFN consists of two stages to update weights (data clustering and weight updating) as described below.

1. Data Clustering

Clustering data aims to get centroid. At this stage, the clustering process will produce the centroid based on closeness to all of the training data. This research uses iRFCM as explained in section 2.2 to set centroid. The centroids are calculated based on training data in each fold. As a result, each fold has a different centroid. The FCM method uses original data in the clustering process [22], whereas iRFCM uses Euclidean distance in the clustering process. The number of clusters used is 5 clusters, and the centroids produced are 5 centroids $\times 11$ columns at each fold.

2. Weight Updating

Artificial neural networks store their knowledge in the weight of their neurons. The number of neurons in RBFN depends on the cluster. This research uses 5 clusters, therefore RBFN has 5 neurons in its hidden layer. The training functions are used to get the weight and bias of the neurons. There is a series of calculations needed to update the weights and also required training data. The steps at weight updates as follows [23].

a. Forward the input signal to the hidden layer and calculate the value of the activation function $(\varphi)$ on each hidden layer using Equation 2.

$$
\varphi_{i, j}=\exp \left(-\frac{1}{\sigma^{2}}\left\|\mathrm{X}_{\mathrm{i}}-\mathrm{t}_{\mathrm{j}}\right\|^{2}\right)
$$

where

$i \quad:$ Index of input vector instances, $i \in\{1,2, \ldots, N\}$, where $N$ total instances,

$j$ : Centroid index, $j \in\{1,2, \ldots, C\}$, where $C$ total clusters,

$X_{i}:$ Input vector $i^{t h}, X_{i}=\left\{x_{1}, x_{2}, \ldots, x_{n}\right\}$, where $n$ total attributes,

$\mathrm{t}:$ Centroid, $t=\left\{\overrightarrow{t_{1}}, \overrightarrow{t_{1}}, \ldots, \overrightarrow{t_{M}}\right\}$, where $\overrightarrow{t_{j}}=j^{\text {th }}$ centroid (vector),

$d$ : Inter-centroid distance matrix. $d=\left\{\left[d_{p q}\right]\right\}$ where $d_{p q}$ is Euclidean distance between $t_{p}$ and $t_{q}$,

$\sigma \quad$ : Spread, where $\sigma=\frac{\max (d)}{M}$.

b. Arrange the Gaussian matrix $(G)$ from calculation results.

$$
\boldsymbol{\varphi}=\left[\begin{array}{cccccc}
\varphi_{11} & \varphi_{12} & \varphi_{13} & \left.\varphi_{14} \mid \boldsymbol{B}\right], & \cdots & \varphi_{1 C} \\
\varphi_{21} & \varphi_{22} & \varphi_{23} & \varphi_{24} & \cdots & \varphi_{2 C} \\
\varphi_{31} & \varphi_{32} & \varphi_{33} & \varphi_{34} & \cdots & \varphi_{3 C} \\
\varphi_{41} & \varphi_{42} & \varphi_{43} & \varphi_{44} & \cdots & \varphi_{4 C} \\
\vdots & \vdots & \vdots & \vdots & \ddots & \vdots \\
\varphi_{N 1} & \varphi_{N 2} & \varphi_{N 3} & \varphi_{N 4} & \cdots & \varphi_{N C}
\end{array}\right], \quad \boldsymbol{B}=\left[\begin{array}{c}
1 \\
1 \\
1 \\
1 \\
\vdots \\
1
\end{array}\right]_{N \times 1}
$$

(c) 2020 The Authors. Published by Universitas Muhammadiyah Malang

This is an open access article under the CC BY SA license. (https://creativecommons.org/licenses/by-sa/4.0/) 

where
$\mathrm{N}$ : Total instance,
C : Hidden unit,
$\boldsymbol{B}$ : Bias vector,
$\varphi$ : Activation function matrix.

c. Calculate a new weight $(w)$ with Equation 3.

$$
w=\mathrm{G}^{+} \mathrm{d}=\left(\left(\mathrm{G}^{\mathrm{T}} \mathrm{G}\right)^{-1} \mathrm{G}^{\mathrm{T}}\right) \mathrm{d}
$$

where
$w$ : New weights,
$G$ : Gaussian matrix,
$d$ : Target training data.

The calculation results in Equation 3 produce a matrix containing new weights $(w)$ as many as the number of clusters and the bias value in the last line. Weight and bias values are used in predictions using testing data.

\subsection{Testing and Performance Measurement}

Testing is performed by calculate the testing data, weight and bias using Equation 4 .

$$
y(x)=\sum_{j=1}^{C} w \varphi\left(\left\|x-t_{j}\right\|\right)+b
$$

where

y : Output,

w : Weight

$\mathrm{x} \quad$ : Input vector,

$t \quad$ : Centroid,

b : Bias value.

The performance of each method is measured by using mean absolute error (MAE), mean square error (MSE), and root mean square error (RMSE) and Mean Absolute Percentage Error (MAPE). The calculations are done by using formulas as shown in Equation 5, Equation 6, Equation 7, and Equation 8 [24].

$$
\begin{gathered}
\text { MAE }=\frac{1}{N} \sum_{j=1}^{N}\left|y_{j}-\hat{y}_{j}\right| \\
\text { MSE }=\frac{1}{N} \sum_{j=1}^{N}\left(y_{j}-\hat{y}_{j}\right)^{2} \\
\text { RMSE }=\sqrt{\frac{\sum_{i=1}^{n}\left(y_{j}-\hat{y}_{j}\right)^{2}}{N}} \\
\text { MAPE }=\frac{\sum\left(y_{j}-\hat{y}_{j}\right) / y_{j}}{N} \times 100
\end{gathered}
$$

\footnotetext{
where

$N \quad$ : Total data,

$y \quad$ : Target,

$\hat{y} \quad:$ : Prediction,

j $\quad:$ Index $1,2,3 \ldots N$
} 


\section{Results and Discussion}

Table 3 shows the performance measurement of iRFCM and FCM method. The results of MAE, MSE, RMSE, MAPE, and accuracy measurements on the entire fold. Each fold of 10-fold testing data produces a different performance. The iRFCM have smaller values than FCM of MAE, MSE, RMSE, and MAPE measurement in each fold or overall average. This testing shows that both iRFCM and FCM can determine centroids and RBFN can perform prediction BOD values. Better accuracy is obtained with iRFCM of $78.35510 \%$ compared to $\mathrm{FCM}$ of $77.16816 \%$ and the accuracy difference of the two methods is $1.18694 \%$. Graphical comparisons of the MAE, MSE, RMSE, and MAPE on each fold can be seen in Figure 2.

Table 3. Performance Measurement on Each Fold

\begin{tabular}{ccccccccccc}
\hline \multirow{2}{*}{ Fold } & \multicolumn{3}{c}{ MAE } & \multicolumn{2}{c}{ MSE } & \multicolumn{2}{c}{ RMSE } & \multicolumn{2}{c}{ MAPE } & \multicolumn{2}{c}{ Accuracy } \\
\cline { 2 - 10 } & iRFCM & FCM & iRFCM & FCM & iRFCM & FCM & iRFCM & FCM & iRFCM & FCM \\
\hline 1 & 0.15715 & 0.16685 & 0.03442 & 0.03752 & 0.18553 & 0.19370 & 25.78814 & 27.06521 & 74.21186 & 72.93479 \\
2 & 0.13786 & 0.15141 & 0.03115 & 0.04014 & 0.17650 & 0.20034 & 19.87724 & 21.15303 & 80.12276 & 78.84697 \\
3 & 0.13836 & 0.14374 & 0.03000 & 0.03101 & 0.17320 & 0.17611 & 19.02512 & 20.21846 & 80.97488 & 79.78154 \\
4 & 0.17512 & 0.18738 & 0.04755 & 0.05215 & 0.21806 & 0.22835 & 24.10848 & 25.98657 & 75.89152 & 74.01343 \\
5 & 0.14670 & 0.15487 & 0.03567 & 0.03870 & 0.18886 & 0.19673 & 19.92578 & 20.67653 & 80.07422 & 79.32347 \\
6 & 0.12243 & 0.13038 & 0.02353 & 0.02620 & 0.15339 & 0.16187 & 16.67727 & 16.89374 & 83.32273 & 83.10626 \\
7 & 0.17364 & 0.17791 & 0.04554 & 0.04657 & 0.21340 & 0.21580 & 28.42425 & 28.76367 & 71.57575 & 71.23633 \\
8 & 0.15708 & 0.17119 & 0.04115 & 0.04454 & 0.20284 & 0.21105 & 27.83104 & 30.11111 & 72.16896 & 69.88889 \\
9 & 0.14836 & 0.17065 & 0.04185 & 0.04726 & 0.20458 & 0.21740 & 17.10935 & 19.71434 & 82.89065 & 80.28566 \\
10 & 0.14493 & 0.14578 & 0.03681 & 0.03800 & 0.19185 & 0.19494 & 17.68235 & 17.73579 & 82.31765 & 82.26421 \\
\hline Min & 0.12243 & 0.13038 & 0.02353 & 0.02620 & 0.15339 & 0.16187 & 16.67727 & 16.89374 & 71.57575 & 69.88889 \\
\hline Max & 0.17512 & 0.18738 & 0.04755 & 0.05215 & 0.21806 & 0.22835 & 28.42425 & 30.11111 & 83.32273 & 83.10626 \\
\hline Avg & 0.15016 & 0.16002 & 0.03677 & 0.04021 & 0.19082 & 0.19963 & 21.64490 & 22.83184 & 78.35510 & 77.16816 \\
\hline
\end{tabular}

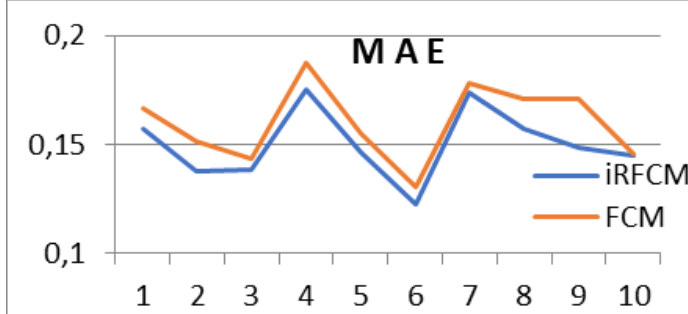

0,25

0,23

0,21

0,19

0,17

0,15

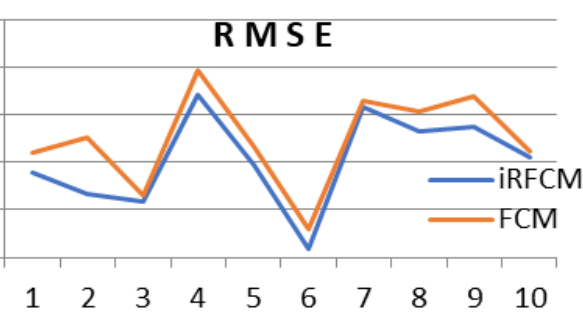

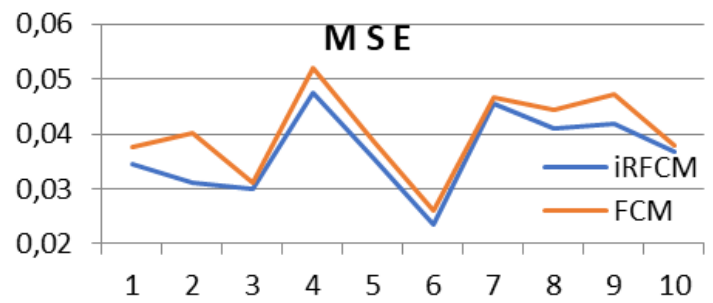

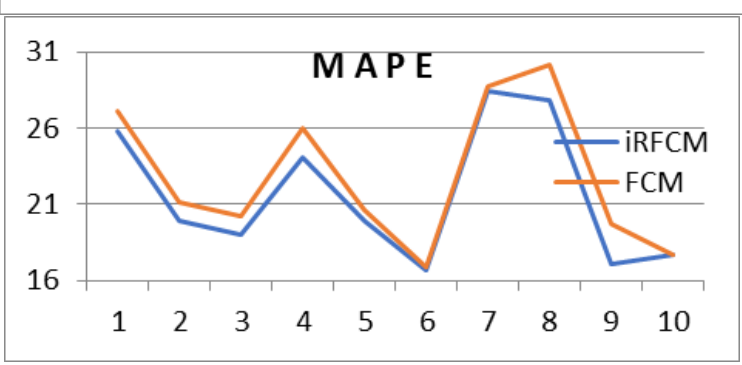

Figure 2. Comparisons of MAE, MSE, RMSE, and MAPE on Each Fold

It is seen that the maximal performance is achieved in the $6^{\text {th }}$ fold (indicated by the smallest error). In general, it is seen that the error at each fold using iRFCM is lower than FCM in every performance measurement. Therefore, in general iRFCM performance is better than the performance of FCM. Figure 3 shows the graphical comparison of prediction accuracy on each fold.

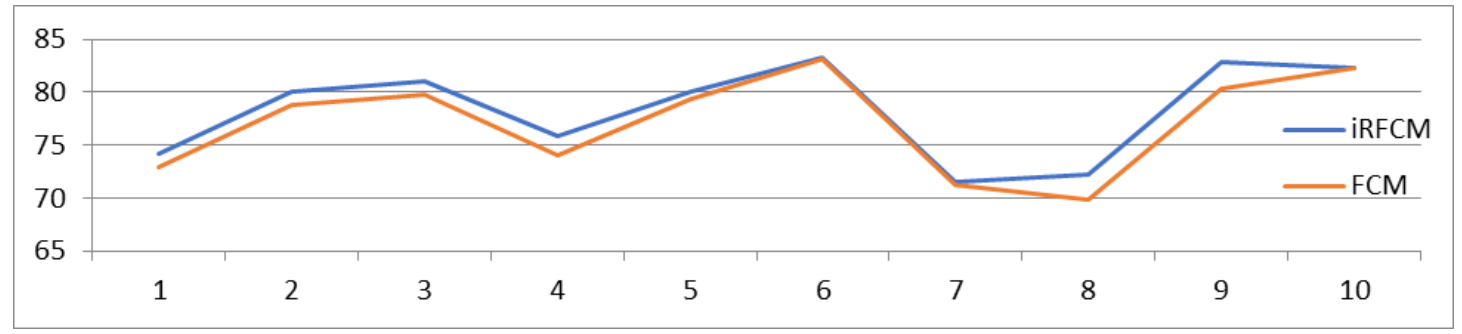

Figure 3. Accuracy on Each Fold

(c) 2020 The Authors. Published by Universitas Muhammadiyah Malang

This is an open access article under the CC BY SA license. (https://creativecommons.org/licenses/by-sa/4.0/) 
The maximum accuracy is in the $6^{\text {th }}$ fold as indicated by the highest accuracy. In general it is seen that the accuracy at each fold using iRFCM is higher than FCM. This conforms with the previous dicussion on MAE, MSE, RMSE, and MAPE. Again in general iRFCM performance is better than the performance of FCM. A comparison of average measurement results with the iRFCM and FCM methods is shown in Table 4.

Table 4. Difference of Average Performance Measurement Results

\begin{tabular}{cccccc}
\hline Clustering Method & MAE & MSE & RMSE & MAPE & Accuracy \\
\hline iRFCM & 0.15016 & 0.03677 & 0.19082 & 21.64490 & 78.35510 \\
FCM & 0.16002 & 0.04021 & 0.19963 & 22.83184 & 77.16816 \\
\hline Difference & 0.00986 & 0.00344 & 0.00881 & 1.18694 & 1.18694 \\
\hline
\end{tabular}

It is seen that the overall performance of prediction using RBFN with iRFCM is better than RBFN with FCM in terms of MAE, MSE, RMSE, MAPE and accuracy performance indicators.

\section{Conclusion}

This research shows that BOD values can be predicted by using both RBFN with iRFCM and RBFN with FCM. Testing results show that RBFN with iRFCM performs better than RBFN with FCM in terms of MAE, MSE, RMSE, and MAPE. Prediction accuracy of RBFN with iRFCM also shows better results than that of RBFN with FCM.

\section{References}

[1] P. R. Indonesia, "PP No. 82 Tahun 2001 Tentang Pengelolaan Kualitas Air dan Pengendalian Pencemaran Air," 2001.

[2] R. Noori, S. Safavi, and S. A. Nateghi Shahrokni, "A reduced-order adaptive neuro-fuzzy inference system model as a software sensor for rapid estimation of five-day biochemical oxygen demand," J. Hydrol., Vol. 495, Pp. 175-185, 2013. https://doi.org/10.1016/j.jhydrol.2013.04.052

[3] A. A. M. Ahmed and S. M. A. Shah, "Application of Adaptive Neuro-Fuzzy Inference System ( ANFIS ) to Estimate the Biochemical Oxygen Demand ( BOD ) of Surma River,” J. King Saud Univ. - Eng. Sci., Vol. 29, Pp. 237-243, 2017. https://doi.org/10.1016/j.jksues.2015.02.001

[4] Salmin, "Oksigen Terlarut (DO) Dan Kebutuhan Oksigen Biologi (BOD) Sebagai Salah Satu Indikator Untuk Menentukan Kualitas Perairan," Oseana, Vol. 30, No. 3, Pp. 21-26, 2005.

[5] A. Solgi, A. Pourhaghi, R. Bahmani, and H. Zarei, "Improving SVR and ANFIS performance using wavelet transform and PCA algorithm for modeling and predicting biochemical oxygen demand (BOD)," Ecohydrol. Hydrobiol., Vol. 17, No. 2, Pp. 164-175, 2017. https://doi.org/10.1016/j.ecohyd.2017.02.002

[6] Nasional Badan Standardisasi, "SNI 6968.72:2009 Air dan Air Limbah: Cara Uji Kebutuhan Oksigen Biokimia (Biochemical Oxygen Demand/BOD)," 2009.

[7] L. Fanjun, Q. Junfei, and Z. Wei, "A Fast Growing Cascade Neural Network for BOD Estimation," 2015 34th Chinese Control Conf., Vol. 2015, pp. 3417-3422, 2015. https://doi.org/10.1109/ChiCC.2015.7260167

[8] J. Qiao, W. Li, and H. Han, "Soft computing of biochemical oxygen demand using an improved T-S fuzzy neural network," Chinese J. Chem. Eng., Vol. 22, No. 11, Pp. 1254-1259, 2014. https://doi.org/10.1016/j.cjche.2014.09.023

[9] E. R. Rene and M. B. Saidutta, "Prediction of bod and cod of a refinery wastewater using multilayer artificial neural networks," J. Urban Environ. Eng., Vol. 2, No. 1, Pp. 1-7, 2008. https://doi.org/10.4090/juee.2008.v2n1.001007

[10] X. Li and J. Song, "A New ANN-Markov chain methodology for water quality prediction," Proc. Int. Jt. Conf. Neural Networks, 2015. https://doi.org/10.1109/IJCNN.2015.7280320

[11] D. S. Broomhead and D. Lowe, "Radial Basis Functions, Multi-Variable Functional Interpolation and Adaptive Networks," R. Signals Radar Establ., no. 4148, 1988.

[12] C. Wang and C. Yan, "Comparison of Four Kinds of Fuzzy C-means Clustering Methods and Their Applications on Posture Classification," Proc. Int. Symp. Intell. Inf. Syst. Appl., Vol. 6, No. 2, Pp. 382-385, 2009. https://doi.org/10.1109/ISIP.2010.133

[13] R. J. Hathaway, J. W. Davenport, and J. C. Bezdek, "Relational Duals of The C-Means Clustering Algorithms," Pattern Recognit., Vol. 22, No. 2, Pp. 205-212, 1989. https://doi.org/10.1016/0031-3203(89)90066-6

[14] Z. Mustaffa and Y. Yusof, "A Comparison of Normalization Techniques in Predicting Dengue Outbreaik," Int. Conf. Bus. Econ. Res., Vol. 1, Pp. 345-349, 2011.

[15] D. A. Nasution, H. H. Khotimah, and N. Chamidah, "Perbandingan Normalisasi Data untuk Klasifikasi Wine Menggunakan Algoritma K-NN," Comput. Eng. Sci. Syst. J., Vol. 4, No. 1, Pp. 78-82, 2019. https://doi.org/10.24114/cess.v4i1.11458

[16] M. Stone, "Cross-Validatory Choice and Assessment of Statistical Predictions," J. R. Stat. Soc. Ser. B, vol. 36, no. 2, pp. 111-133, 1974.

[17] R. Kohavi, "A Study of Cross-Validation and Bootstrap for Accuracy Estimation and Model Selection," Appear. Int. Jt. Conf. Artif. Intell., Vol. 118, No. 4, Pp. 456-461, 1995.

[18] M. A. Banjarsari, H. I. Budiman, and A. Farmadi, "Penerapan K-Optimal Pada Algoritma Knn untuk Prediksi Kelulusan Tepat Waktu Mahasiswa Program Studi IImu Komputer Fmipa Unlam Berdasarkan IP Sampai Dengan Semester 4,” Kumpul. J. IImu Komput., Vol. 02, No. 02, Pp. 5064, 2015. http://dx.doi.org/10.20527/klik.v2i2.26

[19] M. A. Khalilia, J. Bezdek, M. Popescu, and J. M. Keller, "Improvements to the relational fuzzy c-means clustering algorithm," Pattern Recognit., Vol. 47, No. 12, Pp. 3920-3930, 2014. https://doi.org/10.1016/j.patcog.2014.06.021

[20] R. J. Hathaway and J. C. Bezdek, "Nerf C-Means: Non-Euclidean Relational Fuzzy Clustering," Pattern Recognit., Vol. 27, No. 3, Pp. 429-437, 1994. https://doi.org/10.1016/0031-3203(94)90119-8

[21] Y. Kanazawa, "Relational Fuzzy c-Means and Kernel Fuzzy c-Means Using a Quadratic Programming-Based Object-Wise $\beta$-Spread Transformation," Proc. Fifth Int. Conf. KSE 2013, Vol. 2, Pp. 29-43, 2013. https://doi.org/10.1007/978-3-319-02821-7 5

[22] J. C. Bezdek, R. Ehrlich, and W. Full, "FCM : The Fuzzy C-Means Custering Algorithm," Comput. Geosci., Vol. 10, No. 2, Pp. 191-198, 1984.

[23] M. J. L. Orr, "Introduction to Radial Basis Function Networks, Univ. Edinburgh, Pp. 1-67, 1996. https://doi.org/10.1016/0098-3004(84)90020-7

[24] T. Chai and R. R. Draxler, "Root mean square error (RMSE) or mean absolute error (MAE)? -Arguments against avoiding RMSE in the literature," Geosci. Model Dev., Vol. 7, No. 3, Pp. 1247-1250, 2014. https://doi.org/10.3354/cr030079

Cite: Noor, M., \& Buliali, J. (2020). Prediction of Biochemical Oxygen Demand Using Radial Basis Function Network. Kinetik: Game Technology, Information System, Computer Network, Computing, Electronics, and Control, 5(1). doi:https://doi.org/10.22219/kinetik.v5i1.1006 
